\title{
Impact of endoscopic submucosal dissection of an anal squamous intraepithelial lesion with indistinct border
}

A 35-year-old woman, with negative results from a human immunodeficiency virus (HIV) antibody test, underwent colonoscopy that revealed whitish nodules and elevated papillary lesions of various sizes situated in the anal transitional zone ( $\mathbf{F i g . 1}$ ). Biopsy of the whitish nodules revealed high grade squamous intraepithelial lesions. The protruding lesions were distributed almost circumferentially. It was difficult to identify the lateral margins of the high grade squamous intraepithelial lesions with magnified narrow band imaging (NBI) (\$ Fig.1 c, -Fig.2a,b) and indigo carmine dye spraying (• Fig. 1 b).

We performed diagnostic circumferential resection of the involved area via endoscopic submucosal dissection (ESD) ( Video 1).

The procedure was done using a gastroscope (Olympus, Japan) capped with a small-caliber tip attachment (ST Hood short type; Fujifilm, Japan). For local anesthesia a $1: 1$ mixture of $1 \%$ lidocaine and Glyceol (10\% glycerol and 5\% fructose in normal saline solution; Chugai Pharmaceutical, Japan) was injected into the anal aspect of the lesion. ESD was performed using a bipolar needle-knife with a waterjet function (Jet B-knife; Xemex, Japan) and an insulated-tip electrosurgical knife (IT-knife nano; Olympus). The lesion was resected en bloc, uneventfully. The pathological findings were of low grade squamous intraepithelial lesion in the protruding lesions and high grade squamous intraepithelial lesion in the flat area ( $>$ Fig. $3, \triangleright$ Fig.4). The vertical margin was free of tumor, but the anal horizontal margin was difficult to evaluate because of epithelial exfoliation. There was no lymphovascular invasion. Follow-up colonoscopy in 1 year is scheduled.

High grade squamous intraepithelial lesions are precancerous lesions which may progress to invasive cancer [1], and

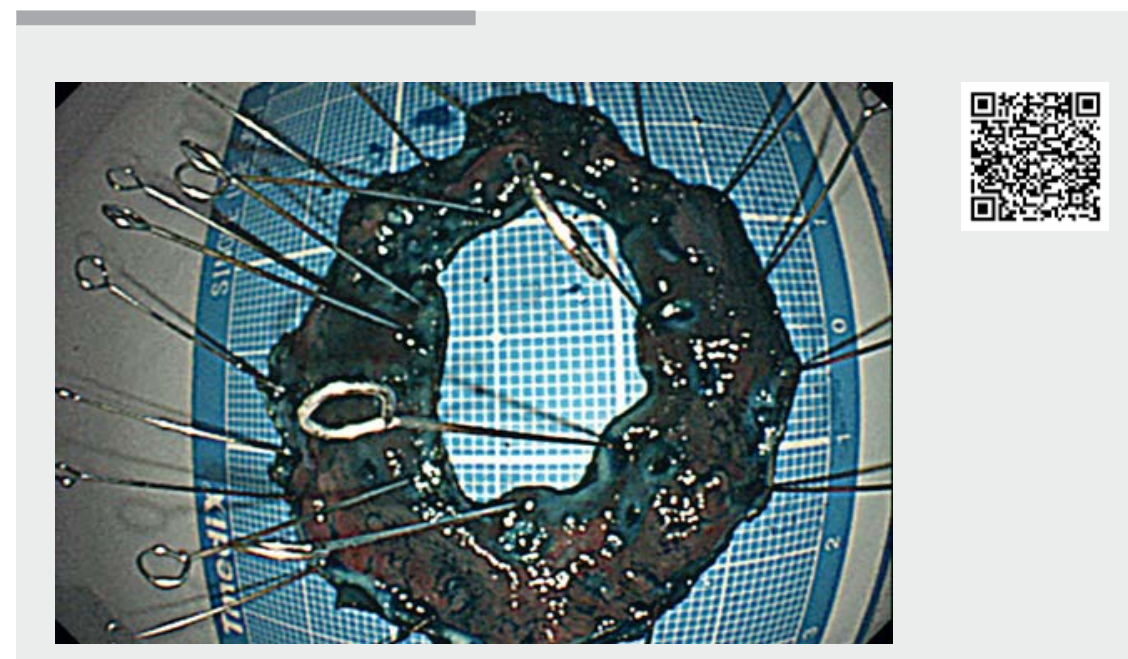

$\nabla$ Video 1 Endoscopic submucosal dissection (ESD) of an anal squamous intraepithelial lesion with an indistinct border.
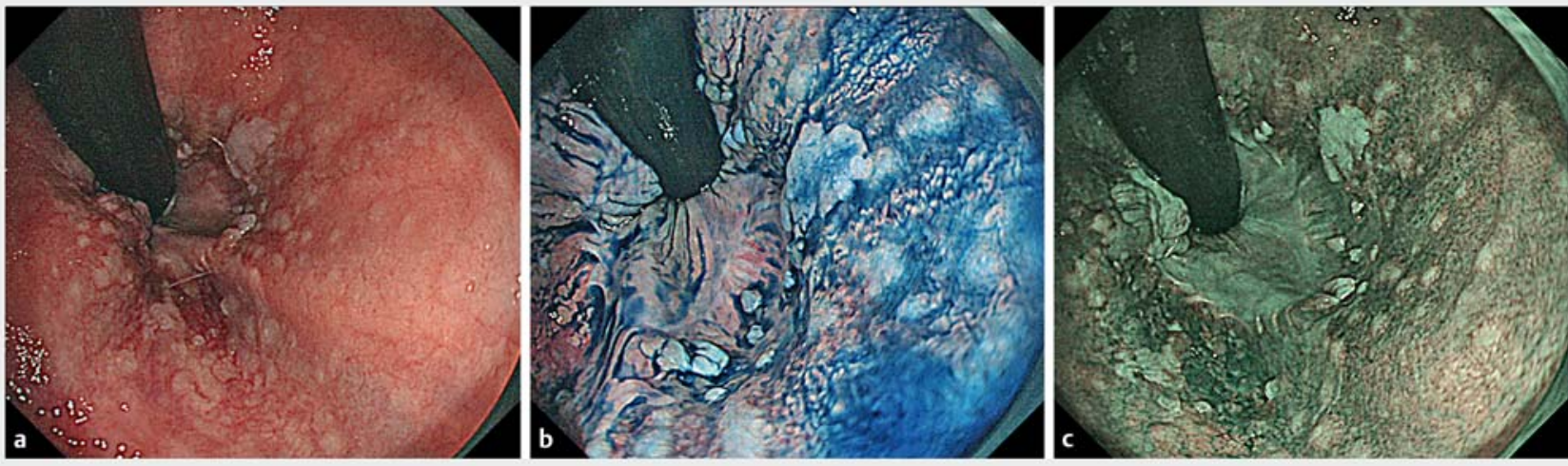

- Fig. 1 Endoscopic images showing whitish nodules and elevated papillary lesions of various sizes in the anal transitional zone: a white light; b chromoendoscopy; c narrow-band imaging (NBI). 

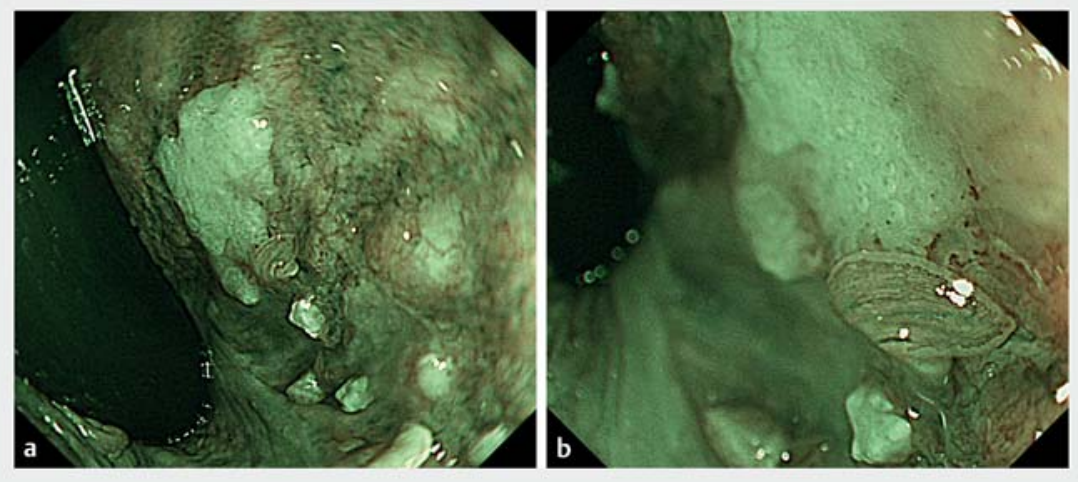

Fig. 2 a, b Narrow-band imaging (NBI) and zoom magnification did not show an abnormal vessel pattern such as intraepithelial papillary capillary loop (IPCL) microvessels.
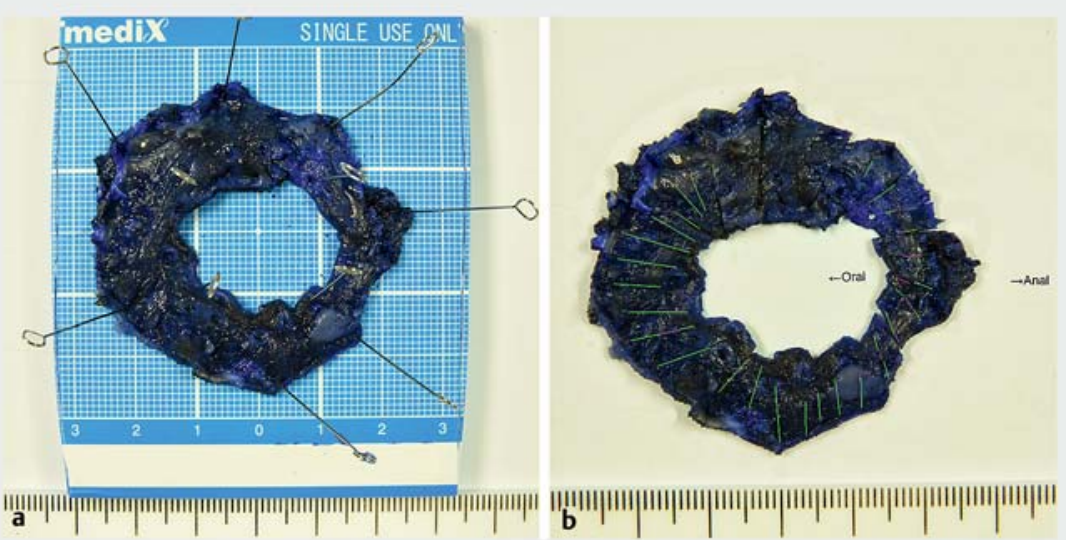

- Fig. 3 Histological examination of the resected specimen. a The specimen is donut-like, and the inner edge is the rectal side, the outer edge is the skin side. b Distribution of the lesions: green lines indicate low grade squamous intraepithelial lesion; pink lines indicate high grade squamous intraepithelial lesion. their management has not been established [2]. We have previously reported the efficacy of performing ESD on early anal canal cancer [3]. Chromoendoscopy and NBI with magnification are useful in delineating the margins of early anal canal cancer [4, 5]. However, it was difficult to delineate the margin even using both methods in this case. The recognition of high grade squamous intraepithelial lesions with indistinct borders, as in this case, is paramount in the prevention of advanced cancer.

Endoscopy_UCTN_Code_TTT_1AQ_2AD

\section{Acknowledgments}

This work was supported in part by The National Cancer Center Research and Development Fund (29-A-13).

The authors are grateful to Dr. Horin Cho, and Dr. Hiroshi Yoshida, National Cancer Center Hospital, for critical discussion on pathological features in squamous intraepithelial lesion.

\section{Competing interests}

None
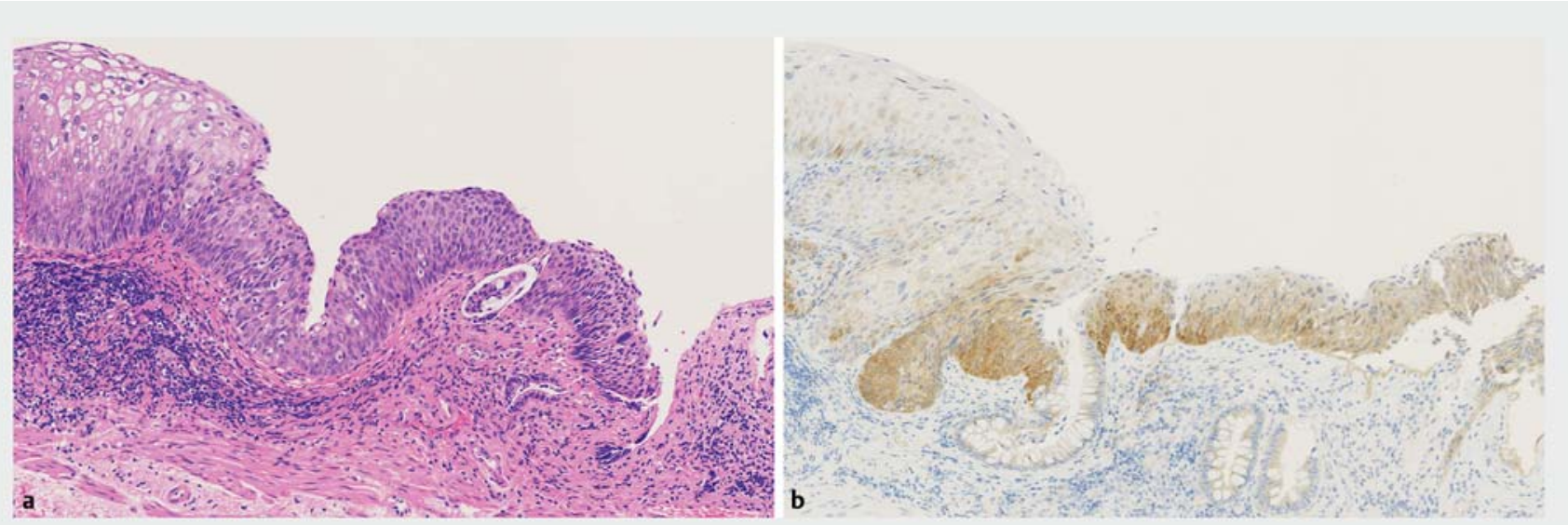

- Fig. 4 The border between the high and low grade squamous intraepithelial lesion. a Hematoxylin and eosin (H\&E) stains, the elevated area on the left side is low grade squamous intraepithelial lesion and shows koilocytosis. In contrast, the area of high grade squamous intraepithelial lesion is rather flat. $\mathbf{b}$ Immunohistochemical staining for $\mathrm{p} 16$ shows a block-positive pattern in the area of high grade squamous intraepithelial lesion. 
Kengo Kasuga ${ }^{1}$, Yutaka Saito ${ }^{1}$, Shih Y. S. Wu ${ }^{1}$, Hiroyuki Takamaru', Taku Sakamoto', Shigeki Sekine $^{2}$, Toshio Uraoka ${ }^{3}$

1 Endoscopy Division, National Cancer Center Hospital, Tokyo, Japan

2 Pathology Division, National Cancer Center Hospital, Tokyo, Japan

3 Department of Gastroenterology and Hepatology, Gunma University Graduate School of Medicine, Maebashi, Japan

Corresponding author

Yutaka Saito, MD, PhD

5-1-1 Tsukiji, Chuo-ku, Tokyo 104-0045, Japan

Fax: ++81-3-3542-3815

ytsaito@ncc.go.jp

\section{References}

[1] Watson AJM, Smith BB, Whitehead MR et al. Malignant progression of anal intra-epithelial neoplasia. ANZ J Surg 2006; 76: 715 717

[2] Alam NN, White DA, Narang SK et al. Systematic review of guidelines for the assess ment and management of high-grade anal intraepithelial neoplasia (AIN II/III). Colorectal Dis 2016; 18: 135-146

[3] Chou Y, Saito Y, Matsuda T et al. Novel diagnostic methods for early-stage squamous cell carcinoma of the anal canal successfully resected by endoscopic submucosal dissection. Endoscopy 2009; 41: E283-E285

[4] Yamaguchi T, Moriya Y, Fujii T et al. Anal canal squamous-cell carcinoma in situ, clearly demonstrated by indigo carmine dye spraying: report of a case. Dis Colon Rectum 2000; 43: 1161 - 1163

[5] Oono Y, Fu K, Nakamura H et al. Narrowband imaging colonoscopy with a transparent hood for diagnosis of a squamous cell carcinoma in situ in the anal canal. Endoscopy 2010; 42: E183-E184

\section{Bibliography}

DOI https://doi.org/10.1055/a-0977-2446

Published online: 17.9.2019

Endoscopy 2020; 52: E75-E77

(c) Georg Thieme Verlag KG

Stuttgart · New York

ISSN 0013-726X

\section{ENDOSCOPY E-VIDEOS}

https://eref.thieme.de/e-videos

回回 Endoscopy E-Videos is a free access online section, reporting 回解: on interesting cases and new techniques in gastroenterological endoscopy. All papers include a high quality video and all contributions are freely accessible online.

This section has its own submission website at

https://mc.manuscriptcentral.com/e-videos 